\title{
Approaches and features of economic efficiency assessment of the infrastructure transport projects
}

\author{
Dmitry Filippov* \\ NEFU Road Construction Faculty, 13, Krasilnikov street, Yakutsk, 677007, Russia
}

\begin{abstract}
This article contains an example of the applied application of the DCR 21-83 guidelines. This article contains a description of the grouped components and assessment criteria, in particular, a description of the calculated indicators in the context of internal transport, non-transport and socioeconomic effects arising from capital investments in transport infrastructure facilities. A specific example shows the procedure for assessing and calculating summary economic indicators for groups and for the project as a whole. This shows the possibility of using a rather complicated methodology and its effectiveness as a scientific tool for a comprehensive assessment for solving applied problems in the construction and rehabilitation of transport infrastructure.
\end{abstract}

\section{Introduction}

Capital investments efficiency assessment in highways infrastructure objects is carried out using departmental building regulations DCR 21-83 (VSN 21-83) "Guidelines for the Assessment of Return on Investment in Construction and Rehabilitation of Roads and Highways" [1]. The existing methodology based on these rules makes it possible to define economic consequences of the realization of investments in transport infrastructure projects. This makes the rules an excellent tool for justifying the economic efficiency of large-scale capital-intensive transport infrastructure projects involving government funding. It allows us to take into account all possible measurable effects that occur not only in transport, but also in the economy and public life of the territory as a whole. At the same time, the application of rules is associated with the need to collect and process a significant amount of statistical information, and to conduct a large number of calculations. As a result, for reasons of high labor intensity, substantial cost, which raises the cost of work at the design stage of the facility, as well as the lack of economic agents in the regions that have the competence and information base to conduct largescale applied scientific research, the use of such an assessment has not been widely adopted. Limitations are also the sufficiency, reliability and quality of the available basic data.

Thus, the initial goal of testing the methodology at the regional level showed not only the feasibility of its use, but also its universal and complex nature, taking into account the effects that arise and are measurable, which is important for assessing the investment qualities of large-scale infrastructure projects with implicit commercial profitability. The

\footnotetext{
*Corresponding author: fil_dv@mail.ru
}

study demonstrated the possibility of using a rather complicated method and its effectiveness as a scientific tool for integrated assessment for solving applied problems in road construction. And its use in combination with dynamic assessment methods based on cash flow analysis can significantly increase the scientific validity of management decisions and the quality of investment projects in the field of transport infrastructure development.

\section{Materials and methods}

Practice shows that the use of this technique is advisable in conjunction with dynamic financial modeling. Since the model allows you to evaluate the aggregated integral indicators based on the analysis of cash flows during the settled period [2]. What is stipulated and regulated by the provisions of the methodological recommendations of VK 477 [3].

The use of the state (national economic) approach is an advantage of the assessment. This approach ensures that all direct and indirect receipts and costs are taken into account not only directly on the assessed road and transport, but in other sectors of the economy of the studied object territory of gravity.

Cost effectiveness is determined by comparing the net cumulative difference between inflows and outflows with the volume of capital investment. Changes resulting from the construction and reconstruction of transport infrastructure facilities are expressed in improving the quality of the road network and, as a result, in reducing transportation costs, reducing economic losses in industry, agriculture and other sectors. That is, improving the satisfaction of the need for the transportation of 
goods and passengers has a positive effect on the value of the national income.

The economic effect consists of the following elements: an increase in net product in industries and profits of organizations in the non-production sphere. Also, the overall economic effect arising from investments in linear objects can be supplemented by accompanying monetized social results. The social result is associated with a reduction in the economic losses of society from road traffic accidents (RTA) and decrease in the loss of passengers' travel time.

\section{Results of research}

The components of the economic effect are internal transport, non-transport and social effects.

1. Consider the internal transport economic effect. It represents the difference between the costs in the reference and design conditions, and also takes into account the profit of enterprises from the implementation of additionally arising transportation. This type of effect is generated during the operation of roads, on vehicles, and during cargo handling.

2. The economic non-transport effect, expressed in the increase in net production, is formed from the reduction of costs and losses in conditions of growth in industries not directly related to the road. This performance category takes into account the incentive effect of highways on industry, agriculture, tourism and other industries.

3. The economic effect in the social sphere. This is a measurable social effect. It includes reducing the travel time of passengers, reducing material losses from road accidents, and environmental damage.

Let us consider the use of DCR 21-83 on the example of the construction of the Nyurba Nyurbachan - Bysytakh - Chukar - Kirov - KhatynSsyy - Zharkhan highway. Under the existing (reference) conditions at the time of the assessment, the road had the following characteristics [4]: the length of $177 \mathrm{~km}$, the length of the all-year-round use section of $27 \mathrm{~km}, 150 \mathrm{~km}$ in the spring and autumn thaw, as well as impassable most of the summer and can only be used as a winter road.

1. Internal transport effect

The project involves the improvement of the technical category of the road. The road surface improves and it becomes year-round. Achievement of design values contributes to the generation of an internal transport effect, in particular:

1. Improving the performance of road maintenance enterprises.

2. Increase in the volume of cargo handling.

3 . Reducing the costs of transport organizations.

4. Growth in the volume of cargo transportation.

5. Growth in income from freight road transport.
Table 1. Summary calculation of the internal transport effect for the period.

\begin{tabular}{|c|c|}
\hline Statement & $\begin{array}{c}\text { Effect, } \\
\text { thousand rub. }\end{array}$ \\
\hline $\begin{array}{c}\text { Increase in income in road } \\
\text { economy }\end{array}$ & 366138,2 \\
\hline $\begin{array}{c}\text { Growth of volumes of loading and } \\
\text { unloading works }\end{array}$ & 1066500 \\
\hline $\begin{array}{c}\text { Reduction of expenses of the } \\
\text { transportation enterprises }\end{array}$ & 616796 \\
\hline Total: & 2049434,2 \\
\hline
\end{tabular}

Total internal transport effect that can be estimated for the entire estimated period of the project will amount to 2,049.4 million rubles.

2. Non-transport effect

It is accepted that the projected road will cause additional cash flow. New receipts will be the result of general economic growth in the branches of material production of the Nyurba and adjacent regions, that is, in the zone of gravity of the new highway.

The calculation of the effect arising outside the direct organizations of the transport complex was carried out in two directions.

1. Since the road becomes year-round, the need to create seasonal stocks of various products (food, fuel, building materials, technical products, consumer goods) is eliminated.

2. The new road stimulates the development of branches of material production. The key industries for our example - the Nyurba region - are: diamond mining, coal mining and agriculture.

The effect of reducing the cost of creating seasonal reserves for the entire calculation horizon will reach 10,607.4 million rubles. For the promising period of the project, the cumulative positive effect in agriculture will amount to 114 million rubles. The effect in the coal industry will be expressed by a decrease in the cost of transporting coal by improving the quality of the road and increasing its technical characteristics. The expected amount of the effect is 1,995 million rubles. for the period of the project.

Table 2. Summary calculation of non-transport effect for the period.

\begin{tabular}{|c|c|}
\hline Statement & Effect, mil rub. \\
\hline $\begin{array}{c}\text { Reduction of expenses for } \\
\text { seasonal stocks }\end{array}$ & 10607,4 \\
\hline Effect in diamond mining & 218,0 \\
\hline Effect in agriculture & 114,0 \\
\hline Effect in coal mining & 1995,0 \\
\hline Total: & 12934,4 \\
\hline
\end{tabular}




\section{Social effect}

The new road will help meet the pent-up demand for passenger traffic. Simultaneously with an increase in the comfort of the speed of transportation. This is very important, since it raises the issue of improving safety, taking into account the harsh natural and climatic conditions of the North and the large distances between settlements. Let us recall that Yakutia is characterized by the isolation of territories and the discrete planning nature of the location of productive forces, energy facilities and settlements.

Therefore, transport infrastructure projects in the northern regions of Russia are distinguished by a more significant impact of social efficiency compared to commercial. That is, the social and environmental effects generated by the infrastructure project become an important and significant factor in assessing the overall economic efficiency of the project and can influence the decision to invest in the construction or reconstruction of the road.

Local or private effects are expressed as follows.

1. Reducing the loss of time of the population during travel.

2. Positive impact on human health due to the reduction of accidents and acceleration of the provision of emergency medical care.

3. Improving the comfort of passenger transportation through the use of high-comfort vehicles (compared to all-terrain vehicles and offroad vehicles), reducing the negative impact of cold air in winter and heat in summer (the territory is characterized by a serious seasonal temperature difference from +35 degrees Celsius to -55 degrees Celsius).

4. Reduction of car accidents on the projected road. The cost estimate of the economic effect of reducing accidents was made based on the maximum amount of insurance compensation for car insurance.

Note that bad and low-quality roads can cause negative social consequences.

1. Mortality due to non-provision or untimely provision of medical care.

2. In areas with low transport accessibility, the development of education, sports and culture is hampered.

3. Reduction of free time of the employed population due to the forced stay on the road.

4. Growth of unemployment.

5. Decrease in transport mobility of the population.

6. Mortality and injuries, including children, due to road traffic accidents.

7. Increased crime due to reduced police mobility.

8. Material losses of organizations and the population from fires and natural disasters due to transport inaccessibility or poor operational quality of highways.

The listed and other consequences, due to the low level of development of the road network, become the reasons for the lack of positive prospects, the outflow of the permanent local population and the possible degradation of the territory in the future.

Table 3. Summary calculation of social effect for the period.

\begin{tabular}{|c|c|}
\hline Statement & Effect, mil rub. \\
\hline Effect of reduction of trip time & 924 \\
\hline Comfort ability & Improvement \\
\hline Reduction of accident rate & 3,2 \\
\hline Reduction of accident rate, $\%$ & $20-25 \%$ \\
\hline
\end{tabular}

Table 4. Summary calculation of economic effect.

\begin{tabular}{|c|c|}
\hline Statement & Effect, mil rub. \\
\hline Internal transport effect & 2049,4 \\
\hline Non-transport effect & 12934,4 \\
\hline Social effect & 927,2 \\
\hline Total effect & 15911,0 \\
\hline
\end{tabular}

Insufficient development of highways and their unsatisfactory condition is a limiting factor in the socio-economic development of any territory.

Table 5. Aggregate economic indicators and calculation of efficiency of capital investments.

\begin{tabular}{|c|c|c|c|}
\hline \multirow[b]{2}{*}{ Statement } & \multirow[b]{2}{*}{ Unit } & \multicolumn{2}{|c|}{ Value } \\
\hline & & \begin{tabular}{|c|} 
Curren \\
$t$
\end{tabular} & Project \\
\hline $\begin{array}{l}\text { Extent of year round } \\
\text { roads, including: } \\
\text { - year-round roads with } \\
\text { hard coating } \\
\text { - winter } \\
\text { Volume of cargo } \\
\text { transportation } \\
\text { Volume of passenger } \\
\text { transportation } \\
\text { Passenger turnover of } \\
\text { the enterprises of all } \\
\text { kinds of activity } \\
\text { Capital investments } \\
\text { Full current expenses } \\
\text { and effects considered } \\
\text { for the period } \\
\text { Coefficient of capital } \\
\text { investments overall } \\
\text { effectiveness }\end{array}$ & \begin{tabular}{|c|}
$\mathrm{km}$ \\
$\mathrm{km}$ \\
$\mathrm{km}$ \\
thousan \\
$\mathrm{d}$ tons \\
thousan \\
$\mathrm{d}$ pass \\
thousan \\
$\mathrm{d}$ pass.- \\
km \\
mil. rub \\
thousan \\
d rub
\end{tabular} & $\begin{array}{c}27,3 \\
150 \\
593 \\
1427 \\
16293\end{array}$ & $\begin{array}{c}5247,8 \\
15911,0 \\
3,03\end{array}$ \\
\hline $\mathrm{E}_{\mathrm{ci}}=15911$ & $47,8=$ & & \\
\hline
\end{tabular}


The cumulative effect of investments in the construction of the road, which is amenable to cost estimation, in three areas of assessment for the entire period will amount to $15,911.0$ million rubles. Table 5 shows the generalized results of calculations and estimates of the efficiency ratio [5].

The calculated value of the overall efficiency indicator (3.03) indicates the positive efficiency and feasibility of investments in the construction of the highway.

As already noted, the performance assessment according to DCR 21-83 can be supplemented by the implementation of a dynamic financial model of the project for VK 477 with the calculation of final integral indicators [6]. At the same time, the example considered by us in this article shows that methodological recommendations for assessing the effectiveness of investment projects well complement the Guidelines for determining the economic efficiency of capital investments in the construction and rehabilitation of highways and proves the feasibility of joint applied use of both methods.

The combination of methodological approaches to the implementation of calculations allows you to calculate the potential effects that can be estimated by value, helps to maximize the cumulative effect by taking into account the positive social consequences. An integrated approach can improve the quality of project development, scientifically substantiate management decisions, and positively influence government decision-making. We believe that such an assessment is necessary when justifying the economic conditions for the implementation of the project to build a bridge across the Lena River near the city of Yakutsk.

\section{Conclusion}

This article contains the results of a study on the applied application of «Guidelines for the Assessment of Return on Investment in Construction and Rehabilitation of Roads and Highways». A concrete example presents the assessment procedure, local and summary calculations of economic indicators by types of efficiency and for the project as a whole. Assessment of internal transport, nontransport and social effects resulting from capital investments in a linear road infrastructure is executed. The results showed the feasibility of applying the guidelines, their universal and complex nature, taking into account the effects that arise and are evaluable, which is important for evaluating the investment qualities of large-scale infrastructure projects with implicit commercial profitability. The study demonstrated the possibility of using a rather complicated method and its effectiveness as a scientific tool for integrated assessment for solving applied problems in road construction [7]. And its use in combination with dynamic valuation methods based on cash flow analysis can greatly enhance the scientific soundness of management decisions and the quality of investment projects in the field of transport infrastructure development.

\section{References}

1. Departmental construction norms of VSN 21-83 «Guidelines for the Assessment of Return on Investment in Construction and Rehabilitation of Roads and Highways». Library of normative documentation, Retrieved from: www.files.stroyinf.ru

2. Erik W. Larson, Clifford F. Gray. Project Management: The Managerial Process (McGraw-Hill, 2011)

3. Department of Economic Affairs of the Russian Federation «Methodical recommendations about assessment of efficiency of investment projects and their selection for financing» (the second edition), No. VK 477. Electronic fund of legal and normative-technical documents, www.docs.cntd.ru (1999)

4. The Federal Law No. 257-FZ «About highways and road activity in the Russian Federation and introduction of amendments to separate acts of the Russian Federation» (2007)

5. Feasibility Study of investments on construction of the highway «Nyurba - Nyurbachan Bysyttakh - Chukar - Kirov - Hatyn-Sysyy Zharkhan» with bridges. (Yakutsk: JSC RPII Yakutproekt, NCP Sakhainfocentre, 2008)

6. N.A. Loginova. Economic assessment of investments in transport (St.Petersburg, 2007)

7. D.V. Filippov, A.E. Ivanova. Amazonia Investiga: Revista Amazonia Investiga Universidad de la Amazonia, 7 (17) 109-120 (2018) 